\title{
Internationalization of the German Higher Education System New Player in the Market
}

\author{
By Mehmet Evrim Altin*
}

\begin{abstract}
Rapid social, financial and political developments in the last three decades have caused some challenges for the future of Higher Education Institutions. Globalization or internationalization is one of the most important challenges in Higher Education Markets in the last two decades. Progressively, in 1996, German legislators put internalization at the center of their reforms. The purpose of this study is to examine the results of these reforms for German Higher Education Institutions in regards to their globalization strategies such as increasing diversity of the students, improving international competitiveness of the German Higher Education Institutions, taking an active role in international EU Projects, conducting cooperation with important international higher education institutions and increasing the brain-drain to German Higher Education Institutions. A qualitative research design was used to study this problem. A multiple unit case study was carried out with semi-structured interviews with 20 high level administrators of the German Higher Education Institutions in the State of North Rhine-Westphalia. The results show that the strategies have had positive results and there is a high interest in higher education studies in Germany today. Despite demographic change in Germany, the student numbers at German Higher Education Institutions are increasing and there is a huge demand from other countries, which have increased the number of private universities in Germany in the last two decades. International competition will be seen as a challenge in the long-term and international cooperation is the strategy to solve this challenge. In the short-term, the number of English Programs and diversity are both seen as some ongoing challenges for the German Higher Education Institutions.
\end{abstract}

Keywords: Internationalization, German Higher Education System, Higher Education and Higher Education Institution.

\section{Introduction}

The German Higher Education System is a very well known, traditional, and high-quality system. At the beginning of the $19^{\text {th }}$ Century, Wilhelm von Humboldt, the director of Berlin University at that time, structured this system. In the last two centuries this system has developed and expanded through all of Germany, Switzerland and Austria. Throughout history, many technological improvements have been made by German scientists, and German thinkers have added important values to universal knowledge. Today, according to the OECD, Germany ranks third in export values after the U.S. and China and German Higher Education Institutions play an important role in the Higher Education world market.

${ }^{*}$ PhD Candidate, Heinrich Heine University Düsseldorf, Germany. 
Unlike the common American Higher Education System, Pasternack and Wissel define the German Higher Education System as a unique higher education structure, based on the Humboldt System (2010). Humboldt suggested that education is a social need and has to be serviced by the state freely. Pasternack and Wissel (2010) also mentioned that academic talent is the only requirement to study in German Higher Education Institutions, and all of the teaching and research costs of the academics have to be covered by the State. Such a system is strictly bound by State regulations and the state puts limitations on the activities of German Higher Education Institutions. These institutions are dependent on state regulations and strictly bound by law. On the other hand, most of these institutions are very well known in university rankings and have very good reputations. Switzerland and Austria follow the German Higher Education tradition and shape their higher education institutions according to this understanding.

The German Academic Exchange Service (DAAD) is the official institution to service the information about the German Higher Education System. According to DAAD, there are four main types of German Higher Education Institutions (HEI), which include Universities, Fachhochschule (FH), Arts \& Music Universities (AMU) and Theological universities (DAAD, 2017). Universities are the top higher education institutions in Germany, and only high school students with an Abitur (High school Graduate Exams) degree can enter these institutions. Fachhochschule, translated in English as Universities of Applied Sciences, are occupation-based and mostly technical institutions. All students, with or without Abitur, can enter these HEIs after fulfilling some requirements of the respective Faculty within the Fachhochschule. Arts \& Music Universities are higher education institutions structured around arts and music, and mostly students with Abitur enter these institutions. Some exceptional entrance cases and unique exams are also possible in Arts \& Music Universities and theological universities.

DAAD reported that, in 2017, there were 106 state and state-recognized private universities in Germany with 1,754,309 students. In addition, DAAD's statistics mention in the same year that there were 246 University of Applied Sciences (Fachhochschule) with 956,928 students and 52 Art, Film and Music universities with 35,607 students. There were also some other religious based or public administration higher education institutions but in general in 2017, 2, 8 million students were enrolled in 427 German Higher Education Institutions (DAAD, 2017). About 17 German universities rank among top 250 universities in the world (THE, 2017).

This traditional, unique system started to globalize in the last three decades and transformed itself according to the worldwide higher education market. The aim of this research is to highlight this change and analyze current strategies of the German Higher Education Institutions (GHEI) such as Quality Management, Capacity Building, increasing competitiveness and diversity management in this change. 


\section{Literature Review}

According to Jane Knight, "Internationalization" in higher education is the process of integrating an international, intercultural or global dimension into the purpose, functions, or delivery of higher education (Knight, 2004). In 1996, German legislators put internationalization in the center of their reforms (Teilcher, 2005). Internalization is a substantial element of university identity. A lack of international activities, transfer of scientific knowledge and information, and change of thoughts and ideas across borders is a sign of an unthoughtful university (Leszczensky \& Barthelmes, 2011). The importance of internalization and competence of the German Higher Education institutions in the markets were acknowledged by the German legislators and there were two main changes that occurred during the globalization of the German Higher Education System in the last three decades.

The first important event was the unification of East and West Germany. After the unification, initially the universities in East Germany transformed their identity and began to copy the structure and policies of the universities in West Germany, which took more than a decade. Before this transformation it was not possible engage on German Higher Education Institutions without considering East and West Germany independently. With this change Universities in East Germany left their ideological philosophy in the higher education system and took science as the center of their work, as it is in West Germany, and rebuilt their structure around a focus on research. The second change was the European Union project that accelerated the globalization of the German Higher Education Institutions. The European Union's project in the political stage also affected the higher education of European countries and Germany. Such a process, which was accelerated during the 1990s, resulted in the signing of the Bologna Process in 1999. Education ministers of 29 European countries came together on the $900^{\text {th }}$ anniversary of the University of Bologna in Italy. They signed the Bologna Agreement, which had three main goals in higher education. These goals were to increase the mobility, international competence ability, and employment ability of students in the EU and candidate countries (Leszczensky \& Barthelmes, 2011).

Germany pays great attention to the Bologna Process. In Germany, in particular, resources are currently flowing into implementing the structures of the Bologna Process at an undergraduate level and continuing education has been shelved (Hanft \& Knust, 2009). Almost all higher education institutions are using this system and it could be said that the Bologna process is established in Germany. To reach the EU goals, German legislators accepted the European Credit Transfer and Accumulation System (ECTS) and transformed their 200 year- old so-called "Diplom-System" to the new commonly known "Bachelor and Master System". There are several differences between these two systems but the most significant change occurs in the study period. During the classical Diplom-System, students have to study five years to get a higher education degree in Germany. However, after the Bologna process, this old system was divided into two parts, the so-called Bachelor's and Master's 
degrees today. The Bachelor's degree takes almost three years, with 180-240 ECTS, and the Master's degree takes 90-120 ECTS, which is almost one and a half years. In this system, one year (two semesters) corresponds to 1500-1800 study hours. After these two degrees comes the third degree, the Doctoral degree, in which no ECTS is used. Unlike the American system, which is based on a four years of Bachelor studies, the Bachelor's degree in EU countries requires three years with a Bachelor's Thesis at the end. In addition to the standardization of the higher education studies in EU, student mobilization (Erasmus and Socrates programs), foreign language development, quality improvement in $\mathrm{PhD}$ studies, increase in exchange programs (Erasmus), and the positive global approach to higher education in Europe are the main achievements of this ECTS system (Teilcher, 2005). Statistics in 2010 demonstrated that there were 102,800 German students studying outside of Germany in 2008, which is $5.8 \%$ of German students in GHEI. This number is twice as large as it was in 1988 (Leszczensky \& Barthelmes, 2011).

According to Leszczensky and Barthlemes, after eleven years of the Bologna Process, national structures have changed and a common HE system is being used, effectiveness and quality standards have increased, and institutional competence ability has grown in the HEI of European Countries (2011). On the other hand, German Legislators and German Higher Education Institutions want to go beyond these achievements and be prepared for the future. The main question in this point is how can German Higher Education Institutions take the world's leading Universities and Research centers position in the future and what kind of measures have to be developed in GHEI to achieve this goal? There are several strategies decided on as a solution for these questions and practiced by German Higher Education Institutions today. These strategies of the German Higher Education Institutions were asked of higher education administrators in Germany during the field study and "Internationalization" became one of the most mentioned strategies by the participants. How this strategy is understood and practiced by the GHE administrators is explained in detail in this paper.

\section{Methodology}

In this research, a qualitative research method was used, involving interviews with administrators of the German higher education institutions. As it was mentioned above, how German Higher Education Institutions take the world leading Universities and Research centers position in the future is asked to the participants. Privatization, Decrease of the state funding, Diversity management and internationalization are some future challenges according to Participants of the Research. From these results, Internationalization of the German Higher Education Institution is analysed in this paper and the current internationalization strategy of these institutions are discussed by the administrators by focusing directly on their opinions of the issue.

There are several methods used in qualitative researches. The case study method is one of the important methods and Yin explains this Method as follows: 
"A case study is preferred when the inquirer seeks answers to how or why questions, when inquirer has a little control over events being studied, when the object of the study is a contemporary phenomenon in a real life context, when the boundaries between the phenomenon and the context are not clear, and when it is desirable to use multiple sources of evidence" (Yin, 2009, p.18)

Merriam defines case study as observing a delimited system deeply and widely (Merriam, 2009, p. 40). According to these views, this study is a case study because the researcher works on a "How" question and he does not have any control over the subject. The researcher used multiple sources and he limited his research to the North Rhine-Westphalia state of Germany and administrators of HEI in this state. There are 16 states in Germany, and North Rhine-Westphalia (NRW) was selected in this research because NRW is one of the biggest states of Germany and four of the biggest cities (Cologne, Düsseldorf, Essen, Dortmund) are in this state. The HE Institutions in this state are examined in regards with the concepts in the conceptual framework with multiple units of analysis. These units of analysis are the institutional structure, educational mission, and financial structure

As each university is considered as a case and multiple units of analysis are used to analyse these cases, embedded multiple case design is used in this research. In Table 1 the list of participants per their institutions are shown.

Table 1. Participants Division per Types of their HEI

\begin{tabular}{|l|c|c|}
\hline & Institution Type & $\mathbf{2 0}$ \\
\hline Structure & & 7 \\
\hline & University & 4 \\
\hline & Fachhochschule & 9 \\
\hline & Technical HEI & 6 \\
\hline & & 11 \\
\hline & Lecture Based & 3 \\
\hline & Researched Based & \\
\hline Financial Structure & Arts \& Music & 13 \\
\hline & & 7 \\
\hline
\end{tabular}

All data in this research were collected by face-to-face semi-structured interviews between September 2014 and June 2015. De Marrais (2004) defines face-to-face interviews as a specific conversation between researcher and interviewer about a field, and questions regarding this field (deMarrais, 2004). Dexter gives a much simpler definition and says that face-to-face interviews are conversations that depend on a specific goal between participants of the discussion (Dexter, 1970).

Merriam defines semi-structured interviews as interviews consisting of open ended questions and describes participant's perception of the world with his or her own ideas (Merriam, 2009). That is why the semi-structured interview 
method is used in this study, which is mainly about the opinions of the participants about the conceptual framework.

The interview protocol was prepared by the researcher with probing questions according to the subject. After that, all interview questions were sent to an expert on qualitative research method and these questions were restructured per the expert's views. The last version of the questions was used in interviews. The following questions were asked during the interviews;

Question 1: Prof. Dr. X, do you think that "internalization" is a real challenge for your institution in the future?

Probe: How do you think German higher education institutions in general and your institution in specific have been influenced by internalization?

Question 2: If we consider the German Higher Education Institutions, could we talk about local or global competition as a challenge in the future perspective?

Probe: What will be the right method to deal with the challenge of competition in the future?

Question 3: What do you think about diversity management in German Higher Education Institutions?

Probe: What are the strategies used by your institution to deal with diversity challenges?

Probe: How do you think it influences the German Higher Education System in General?

As previously mentioned, all interviews were recorded and transcribed. Merriam indicates that the best way to keep data is recording and transcribing it during the data analysis (Merriam, 2009). Bogdon and Biklen advise that it would be better not to lose time between the recording and transcribing part of the interview, because in this time-period the researcher could forget some details or important information about the research (Bogdan \& Biken, 2007).

Taylor and Bogdon (1984) mention that in qualitative research, the names of the participants and institutions need to be protected by nicknames or coded names (Taylor \& Bogdon, 1984). For this reason, the names of the participants and their institutions are coded in this research and this code system is shown in Table 2 below. 
Table 2. Coding of the Institutions and Participants

\begin{tabular}{|c|c|c|c|}
\hline Institutions & $\begin{array}{c}\text { Code of the } \\
\text { Institution }\end{array}$ & $\begin{array}{c}\text { Participants' } \\
\text { Position }\end{array}$ & $\begin{array}{c}\text { Participants' } \\
\text { Code }\end{array}$ \\
\hline Universities & U1 & Dean & U1D \\
\hline & U2 & Rector & U2R \\
\hline & U3 & Vice Rector & U3VR \\
\hline \hline Fachhochschule & FH1 & Rector & U4R \\
\hline & FH2 & Rector & FH1D \\
\hline & FH3 & Vice Rector & FH3VR \\
\hline & FH4 & Rector & FH4R \\
\hline & FH5 & Rector & FH5R \\
\hline & FH6 & Vice Rector & FH6VR \\
\hline & FH7 & Vice Rector & FH7VR \\
\hline Technical HEIs & TFH1 & Vice Rector & TFH1VR \\
\hline & TFH2 & Rector & TFH2R \\
\hline & TFH3 & Vice Rector & TFH3VR \\
\hline & TFH4 & Dean & TFH4D \\
\hline & TFH5 & Vice Rector & TFH5VR \\
\hline \hline & TFH6 & Vice Rector & TFH6VR \\
\hline Arts \& Music & AMU1 & Vice Rector & AMU1VR \\
\hline HEI & AMU2 & Vice Rector & AMU2VR \\
\hline & AMU3 & Rector & AMU3R \\
\hline
\end{tabular}

\section{Results}

In addition to positive results of the Bologna process, like improving quality or facilitating students' mobility, German Higher Education Institutions practice several strategies and try to take the leadership position in the globalization process. Taking an active role in international markets and trying to increase international cooperation with other higher education institutions, especially for the ones which have a high reputation, are one of the current strategies supported by German legislators today. To practice this strategy and achieve the long term of goals of the German Higher Education Institutions, administrators of these institutions practice several strategies. Initially, administrators try to fulfill the quality requirements of the EU standards, which will increase reputations of their institutions on the eyes of the community and investors. Secondly, these institutions are supported and founded by several institutions such as Deutsch Forschungs Gemeinschaft (DFG - German Research Community), foundations like Alexander von Humbold Foundation and the European Union for their research activities. These supports expand the research capacity of these institutions both vertically and horizontally. By increasing their quality and after that their capacity, German Higher Education institutions have increased their competitiveness in international markets and become a stimulating place for other researchers and higher education institutions to 
cooperate. In addition to these steps, German Higher Education grounded several initiatives to follow the international higher education exhibitions, international seminars, advertisement, marketing and international scientific cooperation. The last strategy in internationalization process is the diversity management in German Higher Education Institutions. All of these four strategies are explained separately in this part.

\section{Quality Management in German Higher Education Institutions}

According to the European Association for Quality Assurance in Higher Education (ENQA), quality of education refers to the quality of an institution's teaching and graduates. Institutions generally use employment rates of their graduates, reputation indexes, and quality management activities as basic indicators of the quality of education (ENQA, 2017). Quality is the corner stone during the internationalization process of German Higher Education Institutions and there are three types of quality management institutions in Germany such as: internal quality management offices, private accreditation agencies and the German Council of Science and Humanities (also referred to as WR, Wissenschaftsrat) in Germany.

All of the participants mentioned that they have internal quality management offices in their institutions and quality management teams; they evaluate the courses and try to keep the quality of the programs as high as possible. FH3VR mentioned that: "I think our quality management department does a good job. They do evaluations and questionnaires for every year. This shows annually the quality level of our institution" (personal communication, February 2015). In addition to internal control, German law requires from higher education institutions to apply external private agencies to accredit their programs and also university management. There are several agencies such as the Accreditation Agency for Engineering, Computer and Natural Sciences (ASIIN) or the Agency for Quality Assurance through Accreditation of Study Programs (AQUAS). These agencies have different expertise like technical studies, business studies, natural sciences, et cetera and higher education institutions must apply to these institutions for their programs according to their expertise to evaluate the important elements of programs like the syllabus or academics of the program, and accredit these courses. In addition to these institutions the German Council of Science and Humanities (WR) controls both the institutional quality of some Higher Education Institutions and these external private accreditation agencies in Germany. Old universities and some Universities of Applied Sciences (FH) with a great history or very high reputation are outside of this control. All private universities and new state universities or FHs must be checked by this organization and both the administrative and educational structures need to be approved by this institution. HEIs that have been approved by the WR several times hold a special degree that exempts them from further WR control. FH5R explained this system in detail:

"We have the accreditation law which has two sided, from inside and outside. There are ten different private agencies like FIBAA, AQUAS etc... which 
controls the study programs. They check our programs and also see the practice of these programs. And also on the other hand we have "Wissenschaft Rat" which means Science Commission or Science Committee above these private agencies and they also control us separately. As I said these ten private agencies control the accreditation of our courses and this Science Committee controls our institutional standards. The Science Commission also controls these private agencies and they are the main control organization in the Germany." (personal communication, December 2014)

Internal quality management offices, private accreditation agencies, and the German Council of Science and Humanities (WR) are institutions responsible for working on quality assurance of GHEI and targeted to keep the quality of GHEI above the required EU standards. How the system works is explained by the European Quality Assurance Register for Higher Education (EQAR). EQAR became operative as the "European register of quality assurance agencies, covering public, private, and thematic agencies, operating or planning to operate in Europe" in 2008 (EQAR, 2017). Most of the German Higher Education Institutions achieved EQAR's standards and therefore 17 participants of the study mentioned that their unemployment rate is less than $5 \%$ six months after graduation. OECD reports also support this result:

"Germany is one of the few countries in which unemployment rates have declined continuously, and across all education levels, between 2005 and 2010 and between 2010 and 2012. Between 2005 and 2012, unemployment rates decreased by 7 percentage points among adults without upper secondary education (from $20.1 \%$ to $12.8 \%$ ), by 6 percentage points among those with an upper secondary or post-secondary non-tertiary education (from $11.0 \%$ to $5.3 \%$ ); and by 3 percentage points among those with a tertiary qualification (from $5.6 \%$ to $2.4 \%$ ). By contrast, on average across OECD countries, unemployment rates increased between 2005 and 2012 at each of those levels of education (by 3 percentage points, 1.6 percentage points and 1.1 percentage points, In 2012, unemployment rates at the different levels of education in Germany were below the OECD averages (OECD averages are $13.6 \%, 7.8 \%$ and $5.0 \%$, respectively)". (OECD, 2014)

These statistics demonstrate that the quality of education is not a challenge for the German Higher Education System. Only Arts and Music Higher Education Institutions are an exception due to the current market. These institutions also take some precautions and plan strategies to deal with this issue. One strategy is to combine some programs like "arts and teaching" or "arts and therapy". These strategies could build more bridges between Arts \& Music higher education institutions and the market which will decrease the unemployment rate in the future. 


\section{Capacity Building for International Research Activities}

A second important step during effective role-taking in the internationalization process is supporting universities and scientists in their research activities. German Higher Education Institutions need this support to build and expand their capacity in their research activities and in this way, Higher Education Institutions could fulfill the needs of the industry and have a chance to cooperate and compete with other international higher education institutions in global markets. Such support is sourced from the federal government, local governments and some other private companies and delivered to several foundations in Germany. These foundations cooperate with the universities directly or with the scientists through some specific scholarship programs and fund them in their research projects. The German Research Foundation (DFG Deutsche Forschungs Gemeinschaft) and Alexander von Humboldt foundation are two of the very well-known institutions from several other federal and local foundations in Germany. DFG encourages German Higher Education Institutions in international research activities and announced the following statement about the subject on their annual report in 2016:

"Proposals for research projects with international partners can be submitted at any time within any program in the DFG funding portfolio. The DFG also has agreements with specific countries and regions on special funding opportunities. In addition to project funding, there are funding opportunities designed to intensify international cooperation." (DFG, 2016)

In addition to financial support, which has no time limitation, the DFG also provides funding opportunities designed to intensify international cooperation. These can be used to establish scientific collaborations, organize international scientific events or invite visiting researchers to Germany. Unlike DFG, the Alexander von Humboldt Foundation is an organization which supports researchers at the post-doctorate level and above in their research activities, not institutions. Researchers can apply to Alexander von Humboldt Foundation, without considering their institute or organization that they are working for, and the science committee of the Foundation looks at the qualifications and future research plans of the researcher and supports them if he or she can fulfill the required level.

The research results show that such a support is crucial for research activities. By this method, which is called third party support, higher education institutions increase the research activities in their institutions and help the researchers to provide for their needs. TFH4D mentioned that:

"The main issue here is to find resources for research activities. This is our main problem and that is why we are writing projects and looking for third party support. Otherwise 90 per cent of our budget, which comes from state support, is enough for our educational activities." (Interview, February 2015) 
17 out of 20 participants mentioned that third party support has a complementary role in the whole budget and that solely state support is not sufficient for research activities in German Higher Educations. This kind of support caused two main results, both vertical and horizontal expansion in the research capacity of the institutions. In the horizontal dimension, universities could hire more academics and do more research in different fields. U3VR said that "Third party funds are mainly for research activities and we have roundly 400 professors and 2700 academic staff and they are mainly paid by state but 400 hundreds of the whole number is paid by third party funding"(Interview, February 2015). In the vertical dimension, the institutions could support their high cost research activities easily and get the needed materials even it has high costs.

\section{Increasing Competitiveness of the German Higher Education Institutions}

As mentioned above, globalization and the Bologna process also alleviate evaluation problems and put some standards on Higher Education. EU rules have forced Universities to form their own quality management systems, which increase the quality of their programs (Leszczensky \& Barthelmes, 2011, p. 28). Aside from these changes, most of these countries began to offer English programs, which is much more interesting for the foreign students of Europe. Such improvements make competition a big challenge for Higher Education Institutions all over the world. In addition to this point, due to the development of web-based programs and online studies, competition has become much more important in the Higher Education market. German legislators and higher education administrators saw these results and founded several initiatives and projects to make German universities competitive in international markets. Before explaining these platforms in detail, it is crucial to mention the German Rector's Conference (HRK, Hoschschulrektorenkonferenz) and its role in the German Higher Education System.

The German Rector's Conference (HRK) is the voluntary association of state and state recognized private universities in Germany, which was founded in 1903 with 28 members at that time. Today the HRK has 268 member higher education institutions, where approximately $94 \%$ of all students are enrolled in Germany and HRK plays an important role in internationalization process of the German higher education institutions. Prof. Dr. Horst Hippler, president of the HRK, said that the HRK continuously aims to encourage universities to systematically integrate the international dimension in all their areas of activity. "We need university staff that is sensitized, motivated, and qualified to strengthen internationality and multiculturalism" (HRK, 22 May 2017). As an umbrella organization, HRK considers the competitiveness of the German universities in international markets as a very important subject. HRK establish its supporting duty by founding several methods with its members.

One of these methods is building initiatives that are working on this issue. Germany Internationale Hochschulmarketing (GATE) is one of the most important initiatives which was founded by HRK in cooperation with DAAD. 
GATE-Germany is the largest and most experienced service provider for international university marketing in Germany. With its unique expertise, the consortium supports German universities in the following points:

- To actively and purposefully position itself in the international university landscape

- To present their rich potential professionally and convincingly, to recruit the best minds worldwide

- The German scientific community in the medium and long term is to be internationally attractive and competitive (GATE, 2017)

To achieve these goals GATE gives several services to the German universities like informing them about the international higher education exhibitions and their participation requirements. GATE also provides marketing services, advertises international study programs, language courses, and informs its members from the international seminars, conferences and webinars. Universities can demand consulting from GATE about their internationalization process and also information about the countries or some parts of the world where they want to cooperate. The HRK itself conducted some projects to help its members in their internationalization strategies. The Audit "Internationalization of Universities" project is one of these projects which was started in 2009 with 9 universities. This project is explained in the official website of the HRK as follows:

"The Audit "Internationalization of Universities" helps German universities to approach the internationalization process strategically and to establish it within the institution. The main objectives of the Audit are to assess a university's current state of internationality and (further) develop an institutional internationalization strategy based on this assessment." (HRK, 2017)

In addition to the HRK, the Federal Ministry of Education and Research and other Foundations in Germany created several initiatives to support the competitiveness of German Higher Education institutions in international markets. "Excellence Initiative" is one of the most important initiatives which was founded by the German Research Foundation and the Federal Ministry of Education and Research. This initiative aims to promote cutting-edge research and to create outstanding conditions for young scholars at universities, to deepen cooperation between disciplines and institutions, to strengthen international cooperation of research, and to enhance the international appeal of excellent German universities (Wissenschaftrat, 2017). So far, the German federal and state governments have spent $€ 4.6$ billion between 2006 and 2017 to support so-called clusters of excellence, graduate schools and institutional strategies to promote top-level university research (Böttcher, 2016). In June 2016, the name of this initiative changed to "Excellence Strategy" and the German Chancellor accepted supporting these top level universities with annually $€ 533$ million 
from 2019. The new funding is set to continue indefinitely and initially 11 universities are going to use this money. Four candidate universities are going to apply the Excellence Strategy in 2025.

Such support from different institutions and initiatives has positive effects on German Higher Education institutions. Despite demographic change in Germany, 18 participants of the research out of 20 mentioned that the students' numbers are increasing and the other two participants said that it is remaining constant today. FH6VR expects more increase in the future and reasoned this issue as follows:

Yes, it is clearly increasing and that is why we need more professors or other staff. For example, in 2010 we had less than ten thousand students but today we have more than thirteen thousand students which is almost $35 \%$ more. In the future, I expect more increase in the student number, not as much as today but increase. Because I believe in the following ten or twenty years some of these new founded private universities have to quit and we will get their students. That is why I am expecting more increase in the student numbers (personal communication, January 2015)

Because of this perception, 16 participants out of twenty do not consider "competition" as an ongoing challenge for their institutions. U3VR mentioned that: The student number is increasing in the last two decades and we are not thinking that competition is a big challenge today for our university in this region because of our quality and attractiveness. (personal communication, February 2015) However, all participants expect more competition in the future of the GHEI. In this point, the question is whether "local" or "global" competition will be important in the future of the GHES and various answers were received from the participants.

In this research, $60 \%$ of the participants stated that both global and local competition will be a challenge in the long term, where $30 \%$ consider only global competition as a challenge and $10 \%$ think that local competition will be a challenge in the future of GHES. To have a better understanding about these numbers, it is crucial to look at the types of the institutions where participants work. For example, Research institutions are mainly concerned about global competition. Five participants out of nine mentioned that it will be global and the other four participants mentioned both. However, these four participants highlighted that global competition will be more important challenge than local competition. FH7VR explained this issue as follows:

According to student numbers, it is clearly local more than global competition. Our ninety $\mathrm{X}$ of our students are coming from this region and that is why local. But if we talk about professors or qualified staff, it is clearly global competition. We have to get the best brains to our institution and this is a global market and we have to compete with global actors. And other perspective, if we talk about resources, we are also competing with global competition, because many universities from all over Europe are 
applying to such EU funds and other projects. That is why from Resource perspective we also have to compete internationally (personal communication, January 2015)

On the other hand, teaching institutions are mainly concerned about local competition. This is mainly because the university numbers in Germany have increased in the last two decades and there are many new private higher education institutions which have joined the market. TFH2R highlighted this issue as follows:

Both, we have to be careful and look at the local environment carefully. For example, in Cologne there are a lot of institutions, which have similar programs that we have and it is difficult to survive. I said this tragically. Maybe it is much more difficult in Berlin but in Cologne it is also quite difficult. (personal communication, December 2014)

In addition to type of the universities, the language of the courses are also important in this issue. FH1D gave "Law Faculty" as an example and mentioned that "it is a German law and we are the only market on the planet who are teaching German law and that is why it is local. It is a German pool and all lectures and research is in German." AMU1VR had a similar approach to local competition and explains this issue as follows:

Music is international and we have international challenge. The same case is for dance or design. But if we talk about drama or theater are language based and we could only think about German speaking countries like Germany, Switzerland and Austria. (personal communication, February 2015)

To decrease the local competition between German Higher Education institutions and force them to focus on more international competition, German legislators have wise practices inside Germany. U3VR highlighted this issue as follows:

There are big universities here in this region like Duisburg-Essen University and Technic University Dortmund but we shared the study fields and that is why we could not talk about local competition. That is why we do not compete with these Ruhr region universities but we are collaborating with each other which makes Ruhr region much more attractive... We have an agreement with these universities and students can visit other courses. (personal communication, February 2015)

On the other hand, especially in the courses which could be presented in English and get the best brains for research activities, there is a huge Global competition in international markets. FH3VR mentioned that "To find the best professors or lecturers and also student numbers there will be global competition for GHES and I could say that English spoken countries are much more better position than us because of the language difference." (personal communication, 
February 2015). In addition to this point, FH2R highlighted another issue in global competition and said that "so called Massive Open Online Courses (MOOC) or Archeology Datenexport-Standard (ADEX) online programs could allow the global competitors join the German market and that is another challenge."(personal communication, December 2014)

To deal with especially global competition and to make German higher education institutions more competitive in international markets, participants mentioned that they try to increase attractiveness of the programs, diversifying current programs, servicing more flexible programs (especially with E-Learning) and opening diverse master programs offered to the students. In addition to that, cooperating with foreign HEIs and local companies could increase the reputation of the GHEIs and make GHEIs more competitive in the global market. Focusing on global issues and organizing global events like panels, conferences or seminars are also mentioned this part. Showing the quality of education with marketing activities and advertising important advantages of GHES like the employment rates or the academic staff to student ratio at the GHEI is another strategy that was mentioned. The above-mentioned organizations like German Rectors' Conference, German Research Foundation and different initiatives, like GATE or excellence initiative, collaborate with the German higher education institutions support these activities. This support could be financial funding or strategic consulting universities in their internalization process, like the HRK did in the Audit Project.

\section{a. Diversity Management in German Higher Education Institutions}

The last but not least important subject in the internationalization process is diversity management in German Higher Education Institutions. There are two aspects in this subject which contain as many international students and international academics from different cultures in German higher educational institutions and encouraging and supporting German university students and academics in their international studies. Both aspects are necessary to increase the diversity of the German universities.

The first aspect, the number of foreign students and cultural diversity of the campuses, is a real challenge in the future of German Higher Education Institutions. An OECD report in 2014 also mentioned this approach, and warned that Germany's international education market share is falling.

Having hosted $6 \%$ of all international tertiary students in 2012, Germany ranks third (behind the United States and the United Kingdom) among top destinations for tertiary students enrolled outside their country of origin. However, the share of international students who chose Germany fell by almost three percentage points between 2000 and 2012, as other countries, such as the Russian Federation, attracted an increasing number of international students. (OECD, 2014)

Erasmus statistics also supported this statement. According to these reports, 
the most popular destination among students was Spain, which received 35,386 students, followed by France, the United Kingdom, Germany, and Italy. The results of the research in 2015 have parallel findings to these statistics. 15 participants out of 20 mentioned that it will be a challenge for the future and obstacles in this challenge have to be reduced and removed. The FH2R mentioned that:

Of course, absolutely and it is a positive challenge. More diverse students, colleges or lecturers are better educational offer should be. We are sure that we need it and we have a problematic history as everybody knows that suffers a lot in this point. That is why it is important for us (personal communication, December 2014).

During the interviews, only one participant did not want to mention any percentage about the ratio of the foreign students. The other answers are divided in to three parts such as: less than $10 \%$, between 10 to $20 \%$ and $20 \%$ or more. According to the results, nine participants mentioned that foreign students are less than $10 \%$, six participants mentioned that it is between 10 to $20 \%$ and the other four mentioned that it is more than $20 \%$.

The type of the institution plays important role in this subject. Universities are more diverse institutions than Fachhochschule and Technical HEIs, according to foreign students' numbers. Universities in Germany mostly have good academic reputation and high education quality. For this reason, mostly foreign students prefer or want to study at these institutions and that is why, unlike the general approach, the foreign student percentage is very high at universities. Four out of seven participants mentioned that foreign students take more than $20 \%$ of the students. U2R mentioned that they do not have any strategy to attract more foreign students because they are already coming and with immigrants who have a foreign background, almost $25 \%$ of their students are coming from different cultures or nationalities.

Unlike universities, Fachochschule (University of Applied Sciences) have a lower percentage of foreign students. The majority of the participants (six out of eight) said that they have less than $10 \%$ foreign students. They mentioned that foreign students do not know the difference between universities and FHs and because of this, they have less interest in studying at a FH. However, immigrants in Germany who are coming from different cultures or nationalities, know the system in Germany and have interested in studying at FHs. These students are counted as a German citizen in statistics because they have a German passport. Therefore, TFH4D debates on these statistics and mentioned that:

It is difficult to say. For example we have students who have a German passport but they belong to other nationalities. If we just look at the foreign passport, I could say that we have just $5 \%$ foreign students. However my assumption is $25 \%$ of our students are foreigners. That is why I could approximately say that foreign students take $5 \%$ to $25 \%$ of our whole students (personal communication, February 2015) 
Only participants from Arts \& Music Higher Education Institutions do not consider diversity as a challenge because of have a very high percentage of foreign students in their institutions. This could be mainly because of the reputation of these schools and the success of these institutions against their global competitors. For example, Folkwang Fine Arts University had an award for the highest foreign students percentage in their institution. AMU1VR reported that $40 \%$ of their students do not have a German passport. Additionally he said that:

We have a diversity management team here in Folkwang University and they are focused on especially the language issue. They are giving German courses and students have to have a specific degree. We do not like also that Korean students come together and do not contact with others, I mean managing the diversity is another challenge (personal communication, February 2015)

Precautions against this challenge is also asked to the participants. The most announced strategy to deal with this challenge is to remove differences between universities and FHs. More transparent GHEI have to be structured in Germany for the future. More advertising in the global markets, increasing the $100 \%$ English programs in GHEIs and partnership activities with foreign universities are the other mentioned strategies in the interviews.

The other aspect of diversity management is sending German tertiary students and academics to foreign countries and letting them see different cultures and different kinds of research activities in other parts of the world. Such an experience does not just help German students and academics to research local issues in these regions, but also helps them to expand their vision and world perception. By this way they could produce different kind of methods and solutions in their studies in Germany. The German Academic Exchange Center (DAAD) plays an important role to increase the number of the German students and academics who have an international expertise. DAAD funds support German and international students in their international studies and helps them with different kind of scholarships. DAAD explains its role in its website as follows:

DAAD is the world's largest funding organization for the international exchange of students and researchers...Since it was founded in 1925, more than 1.9 million scholars in Germany and abroad have received DAAD funding. It is a registered association and its members are German institutions of higher education and student bodies. Its activities go far beyond simply awarding grants and scholarships. DAAD supports the internationalization of German universities, promotes German studies and the German language abroad, assists developing countries in establishing effective universities and advises decision makers on matters of cultural, education and development policy. (DAAD, 2017) 


\section{Conclusion}

In the field study of the research, the following research question was examined: "how German Higher Education Institutions take the world leading Universities and Research centers position in the future and what kind of measures have to be developed in GHEI to achieve this goal?" From these questions, Internationalization challenge become a key concept according to participants and in this paper, internalization strategies of the German Higher Education institutions are examined from the perspectives of administrators of these institutions. During the interviews quality management, capacity building for research, competitiveness and diversity management of the German Higher Education institutions are mostly mentioned subjects during the internalization process. Participants' comments are analyzed with the current institutions which are taking an active part in these issues, compared and explained during the results part.

According to these analyses, participants mentioned that Quality Management in German Higher Education Institutions are above the EU standards and therefore quality issue is not an obstacle during the internationalization of the German Higher Education Institutions. On the other hand, the majority of the participants mentioned funding research activities with third party support as a crucial subject and universities need such financial support during the internationalization process. 17 out of 20 participants highlighted that their budget is enough for teaching activities but not for research activities. That is why funding research activities and expanding research capacity level of Universities is a necessity during the internationalization process of the German Higher Education Institutions and several institutions and some other private foundations have tried to fulfill this gap. EU funds are also another source and, therefore, German Higher Education Institutions tried to be more active in this point. The third highlighted challenge against internationalization in interviews is the increasing competitiveness of the German Higher Education Institutions in the international markets. In general, the majority of the participants mentioned that global competition has become a challenge in the future of German Higher Education System. To deal with this issue increasing English courses, cooperating with other international higher education institutions and improving strategies to get the best brains to Germany are mentioned as strategies by the participants. Local competition is also mentioned especially in some specific fields like law or theater which is only carried out in the German language and also in some common programs. Several institutions and some important initiatives like GATE play important role and help universities to become more attractive in international markets. The last subject mentioned by the participants is the diversity management issue in German Higher Education Institutions. All participants accepted that it is an ongoing challenge today and in the future. The German Academic Exchange Service (DAAD) tried to increase the foreign students' numbers in Germany and the number of German Students and academics in their international studies by giving several scholarships. The number of foreign students in Germany is decreasing according 
to OECD reports and only participants from Arts, Film and Music universities mention that the international students make up more than $20 \%$ of all students.

The success of the mentioned strategies and the above mentioned organizations will be seen in the future. However, GHES is a very dynamic system and update itself according to the new changes in the world. Therefore, such researches have to be repeated in the future and the progress of the current steps and new developments have to be measured by the educational scientists for more reliable data.

\section{References}

Böttcher, C. (2016, June 21). New German excellence strategy gets political go-ahead. Chemistryworld. Retrieved from http://bit.ly/2GTKUqI.

Bogdan, R., \& Biken, S. (2007). Qualitative research for education: An introduction to theories and methods. Boston: Pearson.

DAAD. (2017). German Academic Exchange Service. Retrieved from http://bit.ly/1zs $\mathrm{KrEV}$.

deMarrais, K. (2004). Qualitative interview studies:Learning through experience. . In K. d. Lapan, Foundations for Research (S. 51-68). Mahvvah, NJ: Erlbaum.

Dexter, L. (1970). Elite and specialized interviewing. Evanston, IL: North Western University Press.

DFG. (2016). Deutsche Forschungs Gemeinschaft [German Research Foundation]. Retrieved from http://www.dfg.debgerufen.

ENQA. (2017). European Association for Qaulity Assuarance in Higher Education. Retrieved from http://bit.ly/2GTKb9m.

EQAR. (2017). European Quality Assurance Register for Higher Education. Retrieved from http://bit.ly/2GTK5P2

GATE. (2017). Germany International Hochschulmarketing. Retrieved from http://bit.ly/ 2FRWi9z.

Hanft, A., \& Knust, M. (2009). Continuing higher education and lifelong learning. Springer Netherlands. https://doi.org/10.1007/978-1-4020-9676-1

HRK. (2017). Hochschul Rektoren Konferenz [University Rectors Conference]. Retrieved from http://bit.ly/2Hvscyi.

Knight, J. (2004). Internationalization remodeled: definition, approaches, and rationales. Journal of Studies in International Education, 8(1), 5-31. https://doi.org/10.1177/ 1028315303260832

Leszczensky, M., \& Barthelmes, T. (2011). Herausforderung Internationalisierung. Retrieved from http://bit.ly/2GirH4a

Merriam, S. (2009). Qualitative Research, a guide to design and implementation. San Francisco: Josey Bass.

OECD. (2014). Germany - Country Note - Education at a Glance 2014. OECD Indicators.

Pasternack, P., \& Wissel, C. (2010). Programmatische Konzepte der Hochschulentwicklung in Deutschland seit 1945 [Programmatic concepts of university development in Germany since 1945]. Düsseldorf : Hans Böckler Foundation.

Taylor, E. W., \& Bogdon, R. (1984). Introduction to qualitative research methods (2nd ed.). New York: Wiley.

Teilcher, U. (2005). Quantitative und strukturelle entwicklungen des hochschulwesens [Quantitative and structural developments of higher education]. Beltz Juventa. 
Vol. 6, No. 3 Altin: Internationalization of the German Higher Education System...

THE. (2017). Times Higher Education World University Rankings. Retrieved from http://bit.ly/2ptUecK.

Wissenschaftrat. (2017). German Wissenschaftsrat. Retrieved from http://bit.ly/2pw $1 \mathrm{ghR}$.

Yin, R. (2009). Case study research: Design and method (4th ed.). Thousand Oaks, CA: Sage. 